\title{
Boost Converter Topology for PV System with Perturb And Observe MPPT Algorithm
}

\author{
${ }^{1}$ Shridhar Sholapur, ${ }^{2}$ K. R. Mohan, ${ }^{3}$ T. R. Narsimhegowda \\ ${ }^{I}$ M.TECH student, AIT College \\ ${ }^{2} H O D$, EEE Dept, AIT College \\ ${ }^{3}$ Assoc. PROF, EEE Dept, AIT ColChikamagalur
}

\begin{abstract}
In this paper utilization of a boost converter for control of photovoltaic power using Maximum Power Point Tracking (MPPT) control mechanism is presented. First the photovoltaic module is analyzed using SIMULINK software. For the main aim of the project the boost converter is to be used along with a Maximum Power Point Tracking control mechanism. The MPPT is responsible for extracting the maximum possible power from the photovoltaic and feed it to the load via the boost converter which steps up the voltage to required magnitude. The main aim will be to track the maximum power point of the photovoltaic module so that the maximum possible power can be extracted from the photovoltaic. The algorithms utilized for MPPT are generalized algorithms and are easy to model or use as a code. The algorithms are written in $m$ files of MATLAB and utilized in simulation. Both the boost converter and the solar cell are modelled using SimPower Systems blocks.
\end{abstract}

Key words: Boost Converter, MPPT, solar cell, MATLAB, SIMULINK.

\section{Introduction}

The photovoltaic (PV) domain provide one of the most efficient ways of producing energy, with real perspectives in the future, considering the actual situation of the classical power resources around the world. Usually, when a PV module is directly connected to a load, the operating point is rarely at the maximum power point or MPP. The PV array is an unregulated dc power source, which has to be properly conditioned in order to interface it to the grid. The dc/dc converter is present at the PV array output for MPPT purposes, i.e. for extracting the maximum available power for a given insolation level. [2]

Tracking the maximum power point (MPP) of a photovoltaic (PV) array is usually an essential part of a PV system. Renewable sources of energy acquire growing importance due to its enormous consumption and exhaustion of fossil fuel. Also, solar energy is the most readily available source of energy and it is free. The rapid increase in the demand for electricity and the recent change in the environmental conditions such as global warming led to a need for a new source of energy that is cheaper and sustainable with less carbon emissions. [1]

A MPPT is used for extracting the maximum power from the solar PV module and transferring that power to the load. A dc/dc converter (step up/ step down) serves the purpose of transferring maximum power from the solar PV module to the load. A dc/dc converter acts as an interface between the load and the module. By changing the duty cycle the load impedance as seen by the source is varied and matched at the point of the peak power with the source so as to transfer the maximum power. [3]

Therefore, a MPPT technique is required to obtain maximum power from a PV system. MPPT is used in photovoltaic (PV) systems to maximize the photovoltaic array output power, irrespective of the temperature and radiation conditions and of the load electrical characteristics with the use of DCDC converter like buck converter, boost converter and buck-boost configurations.

Maximum Power Point Tracking, frequently referred to as MPPT, is an electronic system that operates the Photovoltaic (PV) modules in a manner that allows the modules to produce all the power they are capable of. MPPT is not a mechanical tracking system that "physically moves "the modules to make them point more directly at the sun. MPPT is a fully electronic system that varies the electrical operating point of the modules so that the modules are able to deliver maximum available power.

Therefore MPPT techniques are needed to maintain the PV array's operating at its MPPT. Many MPPT algorithm are there to obtain the maximum power point of PV cell as listed below

\footnotetext{
$>\quad$ Perturb and observation method

$>\quad$ Incremental conduction method

$>\quad$ Fractional open circuit voltage method

$>\quad$ Fractional short circuit current method

$>\quad$ Fuzzy logic method
} 
The problem considered by MPPT techniques is to automatically find the voltage VMPP or current IMPP at which a PV array should operate to obtain the maximum power output PMPP under a given temperature and irradiance. It is noted that under partial shading conditions, in some cases it is possible to have multiple local maxima, but overall there is still only one true MPP. Most techniques respond to changes in both irradiance and temperature, but some are specifically more useful if temperature is approximately constant

\section{Basic Block Diagram}

The basic block diagram is as shown in figure 1.It consists of Solar panel, DC-DC power converter, MPPT controller, Load. Initially voltage and current from the solar panel is sensed by using voltage and current sensor.

These voltage and current values can be input to the MPPT controller. Later these values can be proceed according into the MPPT algorithm used to track the maximum power point of solar panel. The output of MPPT block is used as input to DC-DC converter which may be voltage parameter or duty cycle. DC-DC converter helps in maintaining the operating voltage at the maximum power point. By varying the duty cycle of DC-DC converter.

Usally Buck, Boost, Buck- Boost configuration is used according to requirement. In this paper Boost converter is used to step up the operating voltage at the maximum power point. DC-DC power converter is connected between the solar panel and load.

The heart of the model is the MPPT block which helps in finding the maximum operating point of solar panel. This can be done by using MPPT algorithms. Which in turn gives gating signal to Boost converter which maintains the operating voltage at the maximum operating point irrespective of solar irradiance and temperature.

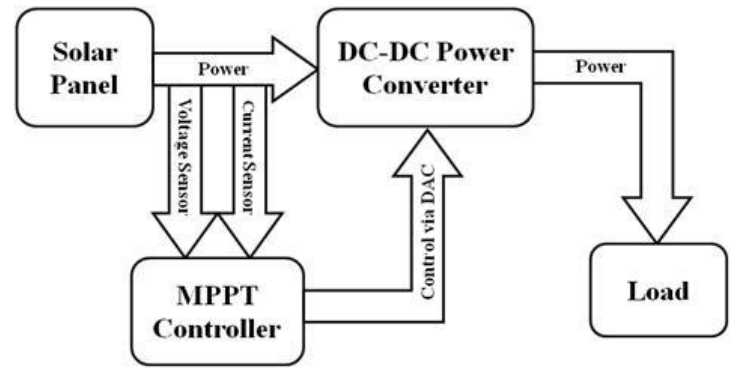

Figure 1: Basic block diagram

\section{Modelling Of Pv Cell}

Figure 2 shows The equivalent circuit of the general model which consists of a photo current, a diode, a parallel resistor expressing leakage current, and a series resistor describing an internal resistance to the current flow in the circuit. [4]

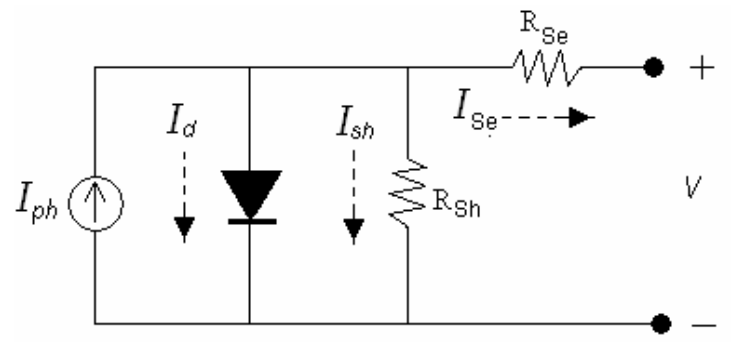

Figure 2: equivalent circuit of PV cell

The current- voltage characteristic equation of a solar cell is given as

$\mathrm{I}=\mathrm{IPh}-\mathrm{ISe} \exp \mathrm{q}(\mathrm{V}+\mathrm{Irs}) / \mathrm{k}$ TCA $-1-(\mathrm{V}+\mathrm{Irs}) / \mathrm{Rsh} . .$. (i)

Where,

$\mathrm{IPh}=$ Light-generated current or photocurrent,

Ise $=$ Cell saturation of dark current,

$\mathrm{q}=1.6 \times 10-19 \mathrm{C}$,

$\mathrm{k}=$ Boltzmann's constant $1.38 \times 10-23 \mathrm{~J} / \mathrm{K}$,

$\mathrm{TC}=$ Cell's working temperature,

$\mathrm{A}=$ Ideal factor,

$\mathrm{RSh}=$ Shunt resistance, 
$\mathrm{RSe}=$ Series resistance

The photocurrent mainly depends on the solar insulation and cell's working temperature, which is described as $\mathrm{IPh}=[\mathrm{Isc}+\mathrm{KI}(\mathrm{TC}-\mathrm{T}$ ref $)] \alpha$

Where,

Isc $=$ Cell's short-circuit current at a $25^{\circ} \mathrm{C}$ and $1 \mathrm{kw} / \mathrm{m} 2$

$\mathrm{KI}=$ Cell's short-circuit current temperature coefficient,

Tref $=$ Cell's reference temperature

$\alpha=$ is the solar insulation in $\mathrm{kw} / \mathrm{m} 2$.

On the other hand, the cell's saturation current varies with the cell temperature, which is described as

I s $=\operatorname{Irs}(\mathrm{T}$ C/T ref) $3 \exp [\mathrm{q} E G(1 / \mathrm{T}$ ref - 1/TC)/ kA]

Where,

Iref $=$ Cell's reverse saturation current at a reference temperature and a solar radiation

$\mathrm{EG}=$ Bang-gap energy of the semiconductor used in the cell.

\section{Boost Converter}

Boost converter is also called as the step up converter as output of Boost converter is always greater than that of the input. Figure 3 shows the schematic diagram of Boost converter. [5]

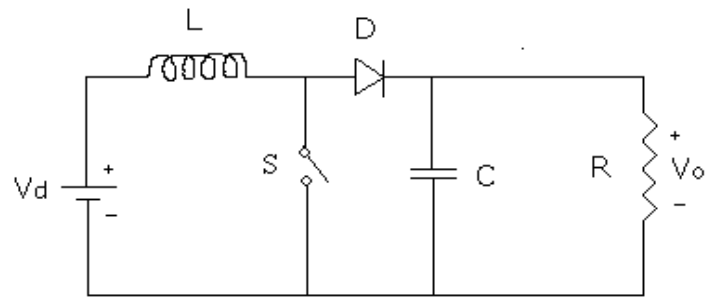

Figure 3: schematic diagram of Boost converter

Boost converter consists of input voltage source, switch, inductor, diode, capacitor and resistor which acts as a load. The switch can be closed or open depends on the output requirement. The output voltage across the load or resistor is always greater than that of input voltage. A boost regulator can step up the voltage without a transformer. Due to a single switch, it has a high efficiency. The input current is continuous. The output voltage is very sensitive to changes in duty cycle $\mathrm{D}$ in equation. The average output current is less than the average inductor current by a factor of (1-D), and a much higher rms current would flow through the filter capacitor.

If the boost converter operates in continuous conduction mode (CCM), then the value of inductance $\mathrm{L}$ from the inductor current ripple analysis is given by equation. [5]

$\mathrm{Lmin}=(1-\mathrm{D}) 2 * \mathrm{D} * \mathrm{R} / 2 * \mathrm{f}$----------- (iv)

The minimum value of filter capacitance that results in voltage ripple $\mathrm{Vr}=\mathrm{deltaVO} / \mathrm{VO}$ is given by equation

$\mathrm{Cmin}=\mathrm{D} / \mathrm{R} * \mathrm{f}^{*} \mathrm{Vr}$

\section{Perturb And Observation Algorithm}

The perturb and observe( $\mathrm{P} \& \mathrm{O})$, as the name itself states that the algorithm is based on the observation of the array output power and on the perturbation (increment or decrement) of the power based on increments of the array voltage or current.

In this method a slight perturbation is introduce system. This perturbation causes the power of the solar module changes. If the power increases due to the perturbation then the perturbation is continued in that direction. After the peak power is reached the power at the next instant decreases and hence after that the perturbation reverses. When the steady state is reached the method oscillates around the peak point. In order to keep the power variation small the perturbation size is kept very small. [1] [3] [5] 


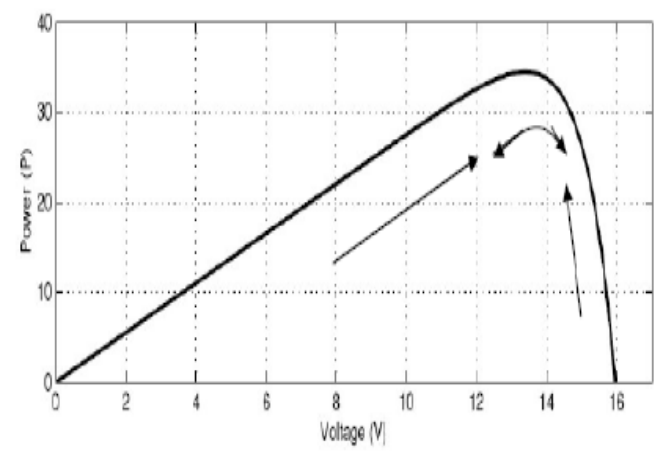

Figure 4: $\mathrm{P}-\mathrm{V}$ characteristics for Perturb and Observe Algorithm

The logic of this algorithm and the flowchart are explained in Figure 5. The operating voltage of the $\mathrm{PV}$ system is perturbed by a small increment of $\Delta \mathrm{V}$, and this resulting change in $\Delta \mathrm{P}$. If $\Delta \mathrm{P}$ is positive, the perturbation of the operating voltage needs to be in the same direction of the increment. On the contrary, if $\Delta \mathrm{P}$ is negative, the obtained system operating point moves away from the MPPT and the operating voltage needs to move in the opposite direction of the increment.[5] [6]

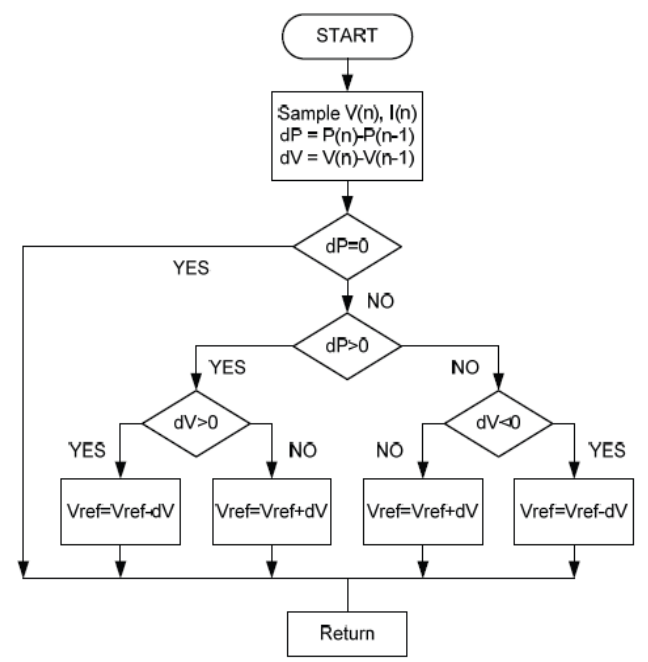

Figure 5: Flow chart of Perturb and Observation algorithm

\section{Simulation Of Model In Simulink}

Modelling of solar cell or PV cell divided into two parts Behavioural PV modelling and Power limited electrical driver. The behavioural model of proposed PV model is based on this equivalent electrical circuit model. Current source, Iph, which is a current produced by the photons, is constant at a fixed value of radiation and temperature .behavioural PV modelling is as shown in the figure 6. [7]

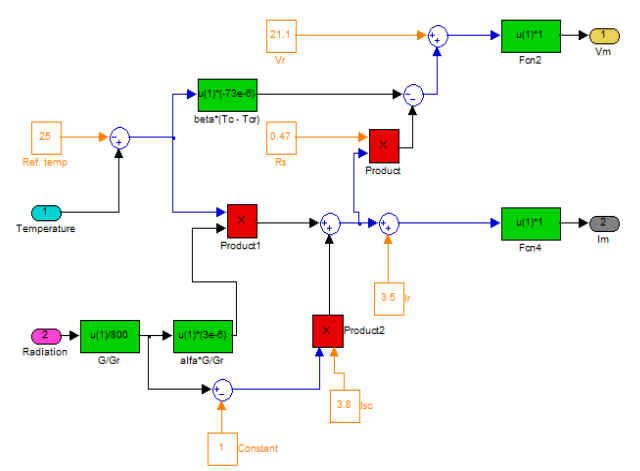

Figure 6: Behavioural PV modelling 
In order to implement PV panel power limits, calculated by the current and voltages values of behavioural model, in the power system, there is need for an electrical driver component that exhibits an I-V characteristic complying with the response of PV panels is as shown in figure 7.

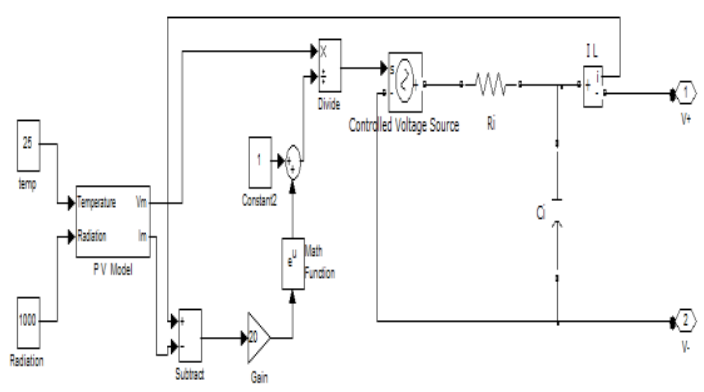

Figure 7: power limited electrical driver

Perturb and observation maximum power point tracking algorithm is developed using SIMULINK software. Is as shown in the figure 8 .

The complete SIMULINK model of the proposed work is as shown in figure 9. Which consists of Solar panel, MPPT block and at the end Boost converter. MPPT block is heart of this work which helps in determining the maximum operating point and also gives the gate signal to the Boost converter. Boost converter helps to maintain the operating voltage at the maximum power point.

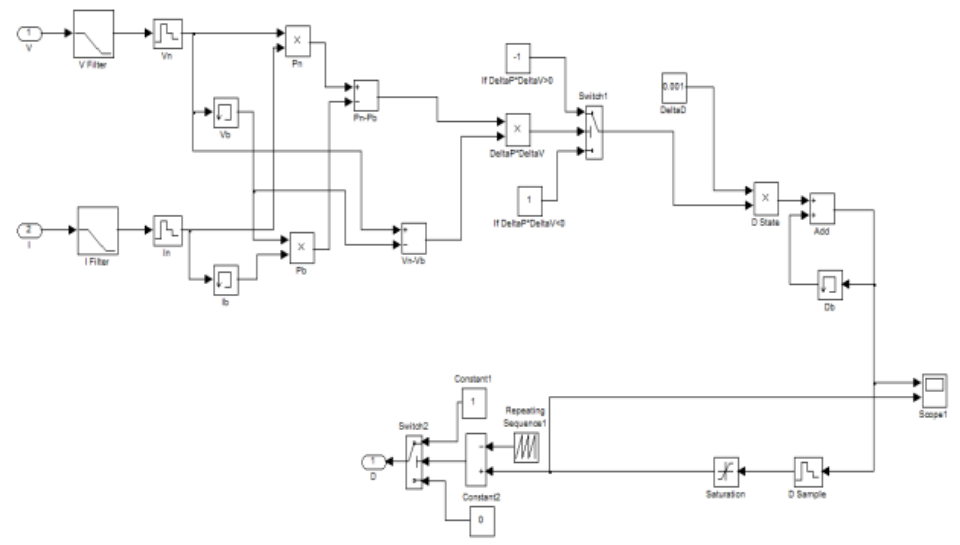

Figure 8: SIMULINK model of perturb and observation MPPT algorithm

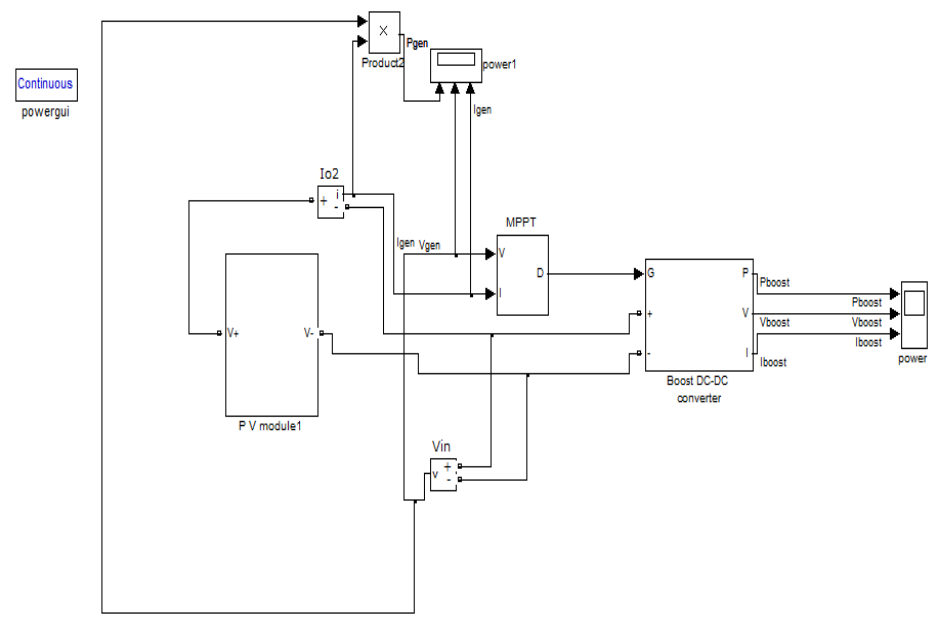

Figure 9: complete SIMULINK model of proposed work 


\begin{tabular}{|l|c|}
\hline MODULE PARAMETERS & VALUES \\
\hline Reference voltage $(\mathrm{Vr})$ & $17.1 \mathrm{~V}$ \\
\hline Reference current $(\mathrm{Ir})$ & $3.5 \mathrm{~A}$ \\
\hline Short circuit current temperature co- & $3 * 10-3 \mathrm{~mA} /{ }^{\circ} \mathrm{C}$ \\
efficient $(\alpha)$ & \\
\hline Open circuit voltage temperature co- & $-73^{*} 10-3$ \\
efficient $(\beta)$ & $\mathrm{mW} /{ }^{\circ} \mathrm{C}$ \\
\hline Short circuit current (Isc) & $3.8 \mathrm{~A}$ \\
\hline Series resistance & $0.47 \mathrm{ohm}$ \\
\hline Internal capacitance & $1.02^{*} 10^{-2} \mathrm{~F}$ \\
\hline
\end{tabular}

Table 2: Parameter settings used for PV module simulations

\section{Simulation Results}

The simulation output waveform form without and with MPPT block is as shown in figure 10 and 11 respectively. It is clear from waveform that at normal operating condition of PV panel output power changes as the solar irradiance varies. This is the condition when the MPPT block and Boost converter is not present. With MPPT block and Boost converter output power remains at maximum power point even though solar irradiance varies.

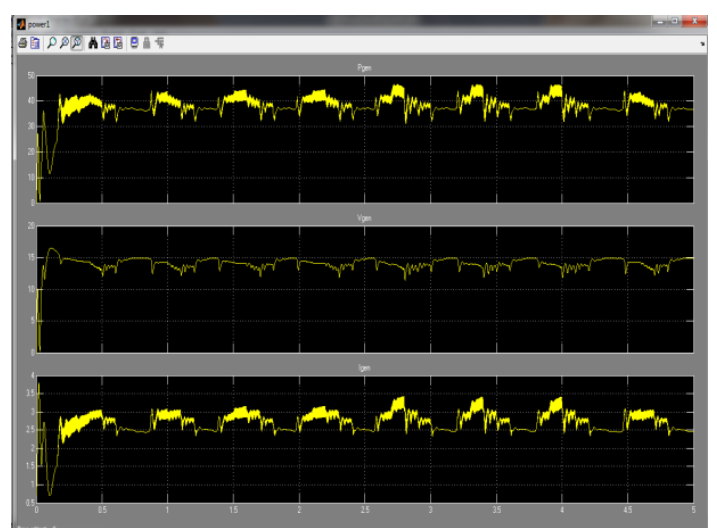

Figure 10: simulation results without MPPT block

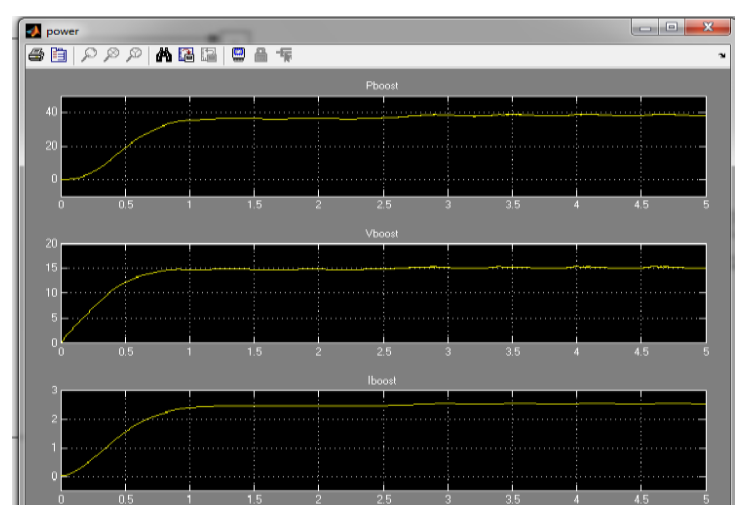

Figure 11: simulation result with MPPT block

\section{Conclusion}

The proposed model is established in SIMULINK software, and output characteristics of photovoltaic array is studied and analyzed. Mainly perturb and observation MPPT algorithm is used to obtain the maximum power point of solar array. Boost converter is used to obtain this maximum power point which helps in step down the array voltage to the maximum operating point voltage. So by using MPPT algorithm and boost converter solar array is operated at maximum power point irrespective of solar irradiance. Further we can also design the inverter circuit which converts the DC power into AC power. And this can be connected to grid with the help of inverter. 


\section{References}

[1]. Literature survey on maximum power point tracking (mppt) technique for photovoltaic (pv) system, Umesh T. Kute, Preeti S. Ratnaparkhi, IJAREAS Vol. 2 No. 12 December 2013.

[2]. Modeling of Maximum Power Point Tracking Algorithm for Photovoltaic Systems, Ioan Viorel Banu,Marcel Istrate "Gheorghe Asachi" Technical University of Iasi.

[3]. Comparison of MPPT Algorithms for DC-DC Converters Based PV Systems, A.Pradeep Kumar Yadav, S.Thirumaliah, G.Haritha, IJAREEIE Vol. 1, Issue 1, July 2012.

[4]. Modeling \& simulation of a photovoltaic energy system, Sonam mishra, Manju gupta, IJEEER Vol. 3, Issue 1, Mar 2013, 61 -66.

[5]. Modeling and Simulation of PV Array and its Performance Enhancement Using MPPT (P\&O) Technique, T.Chaitanya, Ch.Saibabu, International Journal of Computer Science \& Communication Networks, Vol 1(1), September-October 2011.

[6]. Converter topology for PV system with maximum power point tracking, Shridhar Sholapur, K.R.Mohan, IJSR Vol 3 Issue 5, May 2014.

[7]. Mathematical Modeling and Simulation of Photovoltaic Cell using Matlab-Simulink Environment, J. Surya Kumari* and Ch. Sai Babu, IJECE Vol. 2, No. 1, February 2012, pp. 26 34.

[8]. Photovoltaic solar cell simulation of shockley diode parameters in matlab, Awodugba, A. O, Sanusi, Y. K., and Ajayi, J. O, International Journal of Physical Sciences Vol. 8(22), pp. 1193-1200, 16 June, 2013.

[9]. A New Technique for Tracking the Global Maximum Power Point of PV Arrays Operating Under Partial-Shading Conditions, Eftichios Koutroulis, Member, IEEE, and Frede Blaabjerg, Fellow, IEEE, IEEE JOURNAL OF PHOTOVOLTAICS, VOL. 2 , NO. 2, APRIL 2012. 